\title{
An Appraisal of Trade Marketing as a Tool in Managing Distribution Channels in MTN Nigeria
}

\author{
Osungbadegun Isaac Tayo ${ }^{1}$ \\ ${ }^{1}$ National Open University of Nigeria, Nigeria \\ Correspondence: Osungbadegun Isaac Tayo, Department of Business Administration, Faculty of Management \\ Sciences, National Open University of Nigeria.
}

Received: November 15, 2018; Accepted: November 27, 2018; Published: April 1, 2019

\begin{abstract}
Production is not completed until goods and services get to the final consumer, in getting this goods and services across to the consumers, firms employ many channels of distribution. Hence, the traditional channel that involves the distributors and retailers require careful management by manufacturers and suppliers such that their goals and objectives will be aligned and this helps the manufacturer achieve their major objective of getting their goods across to the consumers through the channel. In the management of the channel - trade marketing is employed, that is why this study seeks to appraise the effectiveness of trade marketing in the management of distribution channel and how well this results into increased revenue generation using MTN Nigeria as a case study. The study uses primary data collected through the use of questionnaire which was analysed with simple percentage and ordinary least square with multiple variables. The study finds out that trade marketing activities contributes to increased revenue generation and also discovered that the use or non-use of retailers does not affect the survival of telecom firms due to the development and growth in information and communication technology which helps firm to reach out to their customers via other means different from retailers. The study concludes that telecom firms should balance budget allocation into trade marketing activities as well as other advertisement as a way of resonating their brand in consumer's hearts.
\end{abstract}

Keywords: managing distribution channels, Nigeria, trade marketing, production

\section{Introduction}

In the theory of production, production is said to be complete only when the goods get to the final consumer. While there are different channels of production such as: from manufacturer to consumer, from manufacturer to retailer then to consumer, from manufacturer to wholesaler to retailer and finally to consumer, the latter process is the commonly used in most fast moving consumer goods producer as well as in telecom company. Because of the channels involved in the distribution of goods, there is need to manage the distribution channels. This is what trade marketing seeks to achieve.

Trade marketing is a discipline of marketing that relates to increasing the demand at wholesaler, retailer, or distributor level rather than at the consumer level. To ensure that a retailer promotes a company's product against competitors', that company must market its product to the retailers as well. Trade marketing might also include offering various tangible/intangible benefits to retailers. The alignment of sales and marketing discipline to profitability can be another explanation for trade marketing. (Wikipedia, 2015)

Basic method of trade marketing focuses on sales fundamentals, such as distribution, display, promotion and price. With data and knowledge of sales fundamentals, trade marketing develops market strategy aligned with brand strategy. In order to deliver sales volume and value, trade marketing support sales forces with well-designed fundamental enhancement plans.

The fundamental activities of trade marketing is also derived from the traditional four Ps of marketing. Marketing is defined by the American Marketing Association as "the activity, set of institutions, and processes for creating, communicating, delivering, and exchanging offerings that have value for customers, clients, partners, and society at large." (http://www.saylor.org/books) The traditional way of viewing the components of marketing is via the four Ps:

1. Product - Goods and services (creating offerings).

2. Promotion - Communication. 
3. Place - Getting the product to a point at which the customer can purchase it (delivering).

4. Price - The monetary amount charged for the product (exchange). From this definition of marketing and the components therein, the activities of trade marketing can be seen to focus on the use of these components of promotion, place and price to manage the members of the channel of production.

\section{Literature Review}

In the business of sales or production of consumer goods, reaching out to as many consumers as possible is usually an inevitable goal. That is why many such businesses rely on the support of other business to be able to reach out to as many consumers as possible. In the word of Medi Houghton (2012) "businesses cannot exist in isolation from other stakeholders", it is in the light of this many businesses form alliances in order to acquire larger market share. Some of these stakeholders belong in the channel of distribution as distributors or wholesalers and retailers.

Due to the existence of these channel of distribution and its members, there is need for business to work on maintaining a good supplier-retailer relations. Such relations engender a win-win strategy, (Dupius \& TissierDesbordes, 1996). This channel has become very important because today, marketing channel decisions are as important as the decisions companies make about the features and prices of products. Consumers have become more demanding. They are used to getting what they want. If you can't get your product to them when, where, and how they want it, they will simply buy a competing product. In other words, how companies sell has become as important as what they sell, (Saylor Academy - 2015). The concept of trade marketing has emerged and it focuses on managing the distribution channel with a win-win goal between the producer and all members of the channel.

\subsection{Conceptual Clarification}

The first definition of trade marketing was presented by Lawrence (1983) when he defined the concept as "what the manufacturer must do therefore is to cultivate the development of his marketing policies through the trade by equal attention both to the needs of the consumer and the needs of the distributive trade." According to this definition, trade marketing requires the development of an effective appeal to the distributive trade. Supplier involvement can be one of two, as Lawrence makes the distinction between "active" retailers in which the supplier is involved (either by a franchise set-up, approving the retailer, authorizing the dealership etc.) and "passive" retailers in which the suppliers have no involvement.

Mentioning that there should be a change from the elements of the concept of trade marketing Moore (1994) pointed to some of the key elements in a change the concepts, it is defined in the following way: "A recognition of trade customers' needs and the translation of this recognition into positive, pro-active thinking in the application of sales, marketing, production, distribution and support functions; on a customer-specific basis, to bring about enhanced profitability for customer and manufacturer without compromising brand integrity. Thus, Moore comments on the necessity of changing the managerial mode from reactive to pro-active combined with an internal and external profitability focus. The difficult element of the definition is to avoid compromising brand integrity, while also focusing on the need for customer-specificity. The difference in the definition presented above is also noted by Randall (1994), who defines trade marketing as: "Trade marketing tries to meet the new demands from an increasingly powerful retail trade. The term is so imprecise, and practice so varied, that there is no consensus on what tasks should be included. In practice this can vary from a small group whose job is mainly to collate information for the sales force to a major new department with a board director." - Mogens Bjerre (1999)

In numerous publications, both academic and professional dealing with supplier-retailer relations; conflicts and channel power issues have often been the key words used to characterize those relations. Two major dimensions of conflict have been pointed out: power and performance. Resources and knowledge are two sources of power. Conflicts are often created by perceptual differences. The notion of power has been defined by Stern and El Ansary (1988) as follows: Power is the ability of one channel member to get another channel member to do what the later would not otherwise have done. Power is the inverse of dependence: the more highly dependent one channel member is on another, the more power the latter has relative to the former.

Conflicts and power within a channel have mainly been investigated by studying the dyadic relationship between channel members. Lusch (1976) quoted by Dupius \& Tissier-Desbordes (1996) shows that conflict increases when suppliers are perceived as using coercive tactics, and that these tactics are more common in asymmetrical power relations. At first sight, the word 'conflict' would appear to oppose the term trade marketing, which implies a degree of partnership. However, conflict research is of interest in this current context, for this major reason that trade marketing will not remove all conflicts within a distribution channel; however, it might diminish those that it does not eliminate - Dupius \& Tissier-Desbordes (1996). 
The above definition where trade marketing is seen as those actions and processes that minimises or completely removes conflict within the distribution channel can be considered as logical by weighing the place of consumer in the chain of distribution. Consumers are essential actors in production and subsequent product distribution because it is with a view to satisfying their needs that production is carried out. Kotler (2013) proposed the value chain as a tool for identifying ways to create more customer value. Because of the importance of customer in the supply chain it is paramount that businesses should work more on minimising or removing conflict in the distribution chain so that the main objective would be achieved. These are the major activities of trade marketing as defined by Dupius \& Tissier-Desbordes (1996).

In one of its reviews Fornari (1986) defined trade marketing as a series of actions, the purpose of which is to identify, plan and manage more effectively in order to optimize the use of the company's resources and to obtain a lasting competitive advantage. A trade marketing orientation according Fornari leads to four series of actions:

$>$ estimating the growth potential for each distribution channel and for every member of the channel;

$>$ measuring power relations between suppliers and retailers in the channels in order to determine the possible negotiation issues;

$>$ building a business plan with every client;

$>$ increasing profitability for each channel/client by optimization of company investments.

In France, Jean Chalouin (1992), a consultant, defines trade marketing as a common effort by suppliers and retailers to optimize relations and harmonize resources so as to better serve the consumer and/or try and achieve mutual economies of scale. It is a question of the supplier considering the retailer as a customer, with all that that involves. The retailer is no longer a mere subcontractor, he has become a partner - and more than a partner, he has become a customer and should be treated as such.

Considering these definitions above the key statement of importance in them are similar, for instance Fornari (1986) focuses on optimising the company's resources and the ways to these involve: measuring the growth potential of channel of distribution members, consider the power relations among wholesalers and retailers and build a business plan along this line so that there could be a mutual increase in profitability to both the producer and supply chain members. In the word of Jean Chalouin (1992), relations optimisation and resource harmonisation is the focus of his definition. Relations interaction involves increasing each customer interaction through the delivery of accurate and relevant service and product offers using multi-channel communications, so that there can be improvement in acquisition and retention rates. This still relates to supplier-retailer relationship and management. When all members of a distribution channels pull their resources together and increase interaction with a view to improving relationship this can help place their product in a better competitive position in the market environment.

According to Tissier-Desbordes et al. (1993), trade marketing is a strategic process covering everything that enables the optimization of trading methods between a retailer and a supplier. One of the leading suppliers, Procter \& Gamble (1993) focuses on the state of mind that presides over the implementation of trade marketing in the form of a will to integrate the constraints and the objectives of the partner in order to find the best way to meet his needs and solve his problems. In optimising trade, this is often done with the aid of promotion. Alex Evans and Julie Wherry (2011) identified four-step framework for improving trade promotion programs, the steps are as follows: observe trade promotion effectiveness, measure category price elasticity, evaluate marketplace and competitive dynamics as well as assessing trade promotion options. By the time these four step framework are carried out, a company will be able to achieve long-term results.

\subsection{Trade Marketing Mix}

Since consumer usually do not buy products or services directly from manufacturers but via or from wholesalers and retailers. Trade marketing hence required that besides communicating towards the consumer directly, manufacturers must also ensure that any intermediaries are positioning and promoting their products and services favourably both absolutely and compared to their competitors. Using trade marketing, manufacturers aim to achieve a favourable competitive position at wholesalers, distributors and retailers.

The trade marketing mix are those elements of the marketing mix that relate to increasing the demand at wholesaler, distributor and retailer level rather than at the end-user level. Typical examples of such elements are: trade advertising, trade incentive programs, personal selling, wholesale pricing, payment options, return services, special display, allowances, promotional support and merchandising.

Trade Advertising: consumer-product advertising designed to stimulate wholesalers or retailers to purchase products for resale to their customers. The primary objective of trade advertising is to promote greater 
distribution of the advertised product. This can be done by opening up new outlets for products or by increasing the volume among present outlets.

$>$ Trade Incentive Program: While consumer sales promotions help pull a product through a marketing channel by increasing the consumer's demand for a product, trade sales promotions have the opposite effect. They work to push a product through the channel by increasing a retailer or other intermediary's demand. Trade sales promotion is a promotional incentive directed at retailers, wholesalers, or other business buyers to stimulate immediate sales. Though consumer sales promotions might be the most visible, since they're designed to jump out and grab your attention, trade sales promotions are all around us. They're just not as easily detected by consumers. Manufacturers use trade sales promotions to meet a handful of objectives all geared toward encouraging retailers or other resellers to sell more of their product. For one, if a product is new to the market, a manufacturer may need to offer a trade promotion to encourage a retailer to carry the item. To do so, a manufacturer might offer a free point-of-purchase display along with a trade allowance to attract shoppers to the item. This type of deal might happen at a trade show where a new product is being presented for the first time.

$>$ Wholesale Pricing: manufacturers need to price for profit, it will mean that when planning pricing, they first need to come up with a wholesale price that pays for their time, labour, materials, overhead, employees, etc. This price should have profit built into it so that they are able to not only stay afloat, but grow your business. Once they set the wholesale price, this price is doubled to create retail price ("suggested retail price" to wholesale customers).

$>$ Payment Option: examples of such payment options are discounts and allowances, these are reductions to a basic price of goods or services. Trade discounts and allowances are price reductions given to middlemen (e.g. wholesalers, industrial distributors, retailers) to encourage them to stock and give preferential treatment to an organization's products. There are many purposes for discounting, including; to increase short-term sales, to move out-of-date stock, to reward valuable customers, to encourage distribution channel members to perform a function, or to otherwise reward behaviours that benefit the discount issuer. Some discounts and allowances are forms of sales promotion. Trade discounts are most frequent in industries where retailers hold the majority of the power in the distribution channel (referred to as channel captains). Trade discounts are given to try to increase the volume of sales being made by the supplier. The larger the purchase, the larger the discount. It is important that these discounts are fair and offered to all channel members equally to avoid channel conflict.

$>$ Promotional Support and Merchandising: At a retail in-store level, merchandising refers to the variety of products available for sale and the display of those products in such a way that it stimulates interest and entices customers to make a purchase. The activity of promoting the sale of goods at retail. Merchandising activities may include display techniques, free samples, on-the-spot demonstration, pricing, shelf talkers, special offers, and other point-of-sale methods. According to American Marketing Association, merchandising encompasses "planning involved in marketing the right merchandise or service at the right place, at the right time, in the right quantities, and at the right price." The retail store's shelf is the final battleground for the consumer's dollar. If it's advertising that gets customers into the store, it's merchandising that gets them to select one product over another once they're there. In fact, recent data from the Point-ofPurchase Advertising Institute suggest that 70 percent of supermarket shoppers and 74 percent of massmerchant shoppers make their purchase decision inside the store. For many marketers, this strengthens the case that in-store merchandising just might be more important than media advertising. In-store merchandising is a term applied to any method for maximizing sales at the retail level by making a product stand out from competing products or simply stand out from the clutter of messages in the store environment. It applies to making sure that your product is displayed properly and in sufficient quantity, in its allotted space, with the appropriate merchandising materials, and without other products encroaching on your shelf space. In-store merchandising is also the last chance to present shoppers with information about a product's features, benefits, price, and positioning. Thus it has implications for packaging and the complete array of point-of-purchase (POP) materials, such as product displays, posters, banners, shelf-talkers, and danglers.

\subsection{The Functions and Strategies of Trade Marketing}

As more producers' outlets are dominated by the main retail groups, manufacturers have to sell to the trade first to get space on retailers' shelves alongside own label products. The case for marketing to the trade is increasing and changing (Geoffrey Randall, 1994). This is an indication that manufacturers cannot do it all alone if they will create a competitive niche for themselves in the market. However, as important as these retailers are maintaining 
relationship with them is as important as being successful in business. It is in the light of these Geoffrey argued that manufacturers have two and only two strategies for success: the first is to build and maintain strong brands, then secondly to deliver outstanding customer service to retailers. The first has been neglected recently, which will create disastrous consequences in the medium to long term and the second forces companies to change not only their strategies, but their culture and organizational structures.

The strength of retailers or the trade channel on manufacturers can be considerable except they are managed well. Barbara Nelles (2010) while discussing the manufacturer-retailer relationship, described the relationship as a complex pas de deux (step of two), with many opportunities to work beautifully together to sell more, but also plenty of chances to misstep and trounce on each other's toes. These authors highlights that even though the manufacturer-retailer relationship can be fruitful helping both parties to sell more and thereby creating a better competitive distribution channel, the relationship could be marred with conflicts, this point is further corroborated by Dupius and Tissier-Desbordes (1996) while discussing the historical background of supplier-retailer relationship illustrating with France opined that these relations are traditionally conflict oriented.

With the foregoing, the major functions of trade marketing which therefore dictates or determine the strategy each manufacturers adopt has to do with using the various trade marketing mix as tools to ensuring a smooth relationship between manufacturer and retailer or to ensuring that all members within the channel deliver on their key performance indicators. In the consumer products goods industry, effective trade marketing includes the ability to manage the execution of all trade promotions. This requires an effort by both the manufacturer and the trade customer to ensure that the shelves are properly stocked, the merchandising is in place, displays are stocked, advertising is run (on time, in the media committed) and enough stock is in the pipeline to ensure that the consumers get what they want (m.bizcommunity.com). The essence of these is to optimise sales activities while achieving a sustainable competitive advantage in the market.

In differentiating between trade marketing and shopper marketing, Toby Desforges (2013) identified the key functions of trade marketing. He argued that trade marketing has been with us for more than 25 years. Initially conceived as a function which would organize tailored promotions for large retail customers, it became increasingly important in the '90's. Media fragmentation, retail consolidation and the growth of category management led many large FMCGs to conclude that greater support was needed in managing the trade. So trade marketing developed into a specialist function supporting marketing and sales, charged with the development and execution of point of purchase activities.

Another critical role of trade marketing is to help ensure that (a) both the manufacturer and the retailer is working off the same baseline, (b) that the goals and objectives are aligned. Even though the importance of forming alliances by business organisations cannot be overlooked, it is usually a point of worry for every manufacturer to be concerned about the representation given to them by the different members of the channels. That is why parent organisations in the supply chain have their sales force who work closely with the members of the channel to provide monitoring and some regulatory activities which will certainly ensure that both the manufacturers and retailers have an aligned goals and objectives.

Some other functions of trade marketing are as follows:

$>$ To reach targeted consumer efficiently and effectively, that is to make sure products arrive at retail outlets in an efficient and effective manner in terms of costs, and in the best condition possible. This requires constant supervision and evaluation of the supply chain to ensure brands are delivered using the best distribution methods.

$>$ To focus on guaranteeing product availability, communicating directly with consumers at the point-of-sale, and identifying strategic points of sales in each marketing channel, while also ensuring that there are compliance with applicable marketing regulations as well industry's marketing standards.

Wilkinson (2001) submits that channels of distribution can be viewed as social systems comprising a set of interdependent organizations, which perform all the activities (functions) utilized to move a product and its title from production to consumption. Because of this interdependency there arises a need for some form of cooperation between channel members and co-ordination of activities. This co-operation and co-ordination is necessary in order to ensure predictability and dependability between members which will allow individual organizations to plan effectively. Also, conflict arises in channels, because members sometimes have incompatible goals, differing ideas as to the functions each should perform, and differing perceptions of reality. This conflict needs to be controlled so that it does not disrupt channel functioning. 
In the light of this Kotler and Keller (2013) defined channel power as the ability to alter channel members' behaviour so they take actions they would not have taken otherwise. They outlined five different types of power which can help manufacturers elicit appropriate cooperation from the channel members. The different types of channel power are as discussed below:

1. Coercive Power: A manufacturer threatens to withdraw a resource or terminate a relationship if intermediaries fail to cooperate. This power can be effective, but its exercise produces resentment and can lead the intermediaries to organise countervailing power.

2. Reward Power: The manufacturer offers intermediaries an extra benefit for performing specific acts or functions. Reward power typically produces better results than coercive power, but intermediaries may come to expect a reward every time the manufacturer wants a certain behaviour to occur.

3. Legitimate Power: The manufacturer requests a behaviour that is warranted under the contract. As long as the intermediaries view the manufacturer as a legitimate leader, legitimate power works.

4. Expert Power: The manufacturer has special knowledge the intermediaries value. Once the intermediaries acquire this expertise, however, expert power weakens. The manufacturer must continue to develop new expertise so intermediaries will want to continue cooperating.

5. Referent Power: The manufacturer is so highly respected that intermediaries are proud to be associated with it.

Coercive and reward power are objectively observable, legitimate, expert and referent power are more subjective and depend on the ability and willingness of the parties to recognise them.

Power or, rather, the use of power by individual channel members to affect the decision making and/or behaviour of one another (whether deliberate or not), is the mechanism by which the channel is organized and orderly behaviour preserved. This is not meant to imply that organizations necessarily set out deliberately to organize the channel, but that this organization of the channel arises out of individual organizations adjusting their behaviour to one another in relation to the power they each have and use. However, in some channels, firm(s) may assume a leadership role and make deliberate attempts to organize the channel, making use of their power. Power is the means by which co-operation between individual channel members' activities are co-ordinated and the means by which any conflict between firms is controlled.

Wilkinson (2001) argued therefore that the study of power must be an important part of the study of distribution channel behaviour and will have important implications for the study of physical distribution management. Moreover, the study of power is of increasing importance today as the need for effective co-operation and coordination of activities between channel members grows. Two basic, though not necessarily unrelated, forces underline this trend. First, with the increasing rate of technological change being experienced today and the constant introduction of new products, the tasks of marketing become more complex and, as Alderson (1954) has argued: "The more complex the marketing task becomes the more necessary it is for a channel to operate as an integrated whole in order to attain efficiency". Channels cannot operate as integrated wholes without effective cooperation and co-ordination between their members. The second force concerns the changing nature of the environment which channels are facing in the recent times. In a general context the type of environment increasingly facing organizations of all kinds is such that no longer can individual organizations cope effectively by themselves. One aspect of this is the situation of the organizations comprising a distribution channel. The rise of consumerism and the increasing concern being given to man's effects on his natural environment create problems with which individual organizations cannot cope alone. Partly, these problems can be met by better cooperation and co-ordination between organizations in distribution channels. However, these environmental changes also suggest the need for some degree of co-operation and co-ordination between whole channels. These two forces increase the importance of the study of power because co-operation and co-ordination require some form of power structure.

Seeing now what the degree of conflict and the use of power may produce could eventually disrupt channel performance and, therefore, firms need to search for the least conflict-charged methods of using their power. The conflict generated is also important because it can stimulate those being influenced to search for means of exercising countervailing power, which could result in legal/political pressure being brought to bear that may not be in the best interests of the channel.

Lawrence (1983) introduces the notion of the "Twin Marketing Strategies", one aiming at the consumer and one aiming at the distributive trade. The basic thoughts related to these two strategies regard the retailers as channel members, and the supplier's reaction is one of adaptation of the selling strategy to the individual retailers. Thus 
trade marketing has two primary focuses, one focus is the retail organization including the retail buyer and marketing manager, and the individual store manager, and the other focus is the end-user(s) shopping-pattern in the store(s). Trade marketing focusing on marketing to the retailer and will often encompass generally applicable elements such as general trade developments (trends), retailer trends from other (and perhaps more developed markets), the positioning of the specific supplier vs. other suppliers, trade promotions.

Retailers goals are (apart from realizing their overall strategies) often centered on increasing their share of consumers' total shopping expenditure, on increasing the average size of shopping baskets. This often implies that more than one supplier needs to be involved and this may lead to a situation where the retailer combines the forces of more than one supplier. Trade marketing focusing on marketing to the end-user(s) consists of the following parts - this is sometimes labelled the in-store part of trade marketing and encompass elements such as end-user promotions (price, competitions, etc.), signs, pallet-wrappings, and displays, the ongoing monitoring results.

Lawrence (1983) explicates the twin marketing strategies by claiming, that the business mission: "... sub-divides itself into the two complementary strategies, one for the marketing of the product range to its consumers, and simultaneously one for achieving this marketing through the distributive trade." Lawrence indicates that the retailers take care of the distributive function within the supply chain, however as the retailers are developing the own marketing positioning they do no longer regard themselves as distributors.

The growing importance of trade marketing is also mentioned by Corstjens and Corstjens (1995), as they introduce another strategic perspective for trade marketing, they claim that: "Trade marketing has grown in importance and must change in nature. Trade marketing means managing a strategy triangle: balancing customer value with customer profitability while avoiding customer dependence." However, Corstjens and Corstjens (1995) also points to a central difference between trade marketing and consumer marketing as they underline that: "Trade marketing is industrial marketing business-to-business marketing. In essence, trade marketing is a balancing act involving three issues: first, maximizing the value offered to retailers, second, ensuring the profitability of individual accounts, third, since the client base is much more concentrated in industrial markets, the danger of dependence is much more dramatic."

Relationship marketing is a useful concept for understanding customers, and this is another perspective of trade marketing strategy highlighted by Geoffrey Randall (1994) where argued that manufacturers must have a better understanding of their customers (retailers) to enjoy a better supplier - retailer relationship. Expanding on this idea Bollen A. and Emes C. (2008) examines the extent to which the metaphor of personal relationships can be applied to interactions between individuals and companies, focusing on the customer relationship from the viewpoint of the customer rather than the supplier.

Relationships are not the same; customers want and expect different things from their relationships with different organisations, just as they have different needs and expectations from their varying personal relationships. In interpersonal relationship theory, relationships have been categorised by (i) the types of bond that join parties together (what ties us together?) and (ii) the nature of the benefits they offer each party (what's in it for me?). Bonds between customers and suppliers are changing. The balance of power has shifted towards customers, as new technology has redressed the imbalance in the flow of information between customers and suppliers. Customers now not only have more information and a greater choice but are also able to voice their dissatisfaction more loudly. The shift in the balance of power has contributed to a change in customers' expectations. Companies are now expected to pay more attention to caring for customers, and customers put greater emphasis on honesty and integrity, demanding more transparency from suppliers.

Organisations need to consider relational benefits from the customer perspective, as this will help them understand how to strengthen the customer relationship and achieve desired loyalty outcomes. One study identified three categories of relational benefit: confidence benefits, social benefits and special treatment benefits - (Bollen \& Emes, 2008). But there are additional relational benefits from the customer perspective. Relationships can be considered to be purposive; a shared commitment to helping the environment is one way in which customers and suppliers can provide meaning to their relationship. Customers are also increasingly expecting relationships to offer experiential benefits. As products and services have become commoditised, that is why companies are now building businesses around offering experiences where they engage customers and connect with them in a personal and memorable way.

It suffices at this point to quote Mogens Bjerre (1999) when he says "there has not been developed any model or listing of arguments, presenting the reasons why one should choose one solution and not the other. Nor has there been developed any form of normative statements indicating when different elements of trade marketing may be appropriate or not". This argument shows that there are no particular structured strategy for resolving the issues 
around manufacturer-retailer relationship. The relationship even though it is essential, however it also complex and complicated, as described by Corstjens and Corstjens (1999) that "co-operation between retailers and manufacturers is possible in some areas, but fundamentally their interest conflict. Both are seeking to control the same scarce resources: mind-space (the consumers) and shelf-space (the shops). Partnership, if it is to be called that, needs to be sought from a position of strength: affecting the balance of power is a major aim of marketing strategy, for both retailers and manufacturers".

\section{Methodology}

This section describes and explains the methodology deployed in this study. The survey research design method is adopted for used in this study. It involves the collection of information from a sample of individuals through their responses to questions. It also involves the use of a self-designed questionnaire in collecting data from the respondents (Andres, 2012).

The population of this study comprises the retailers who occupy the last stage in the chain of distribution. The Business Dictionary defines retailers as a business or person that sells goods to the consumer, as opposed to a wholesaler or supplier, who normally sell their goods to another business. As far as the case study for this research is concerned these retailers are referred to as Biz Lift Members - a term coined from business lift members. This indicate their importance as well as their roles in making products and services available to consumers or end users, that is why more trade marketing activities are carried out around them. This study population is an infinite figure - retailers are everywhere around the corners of the street in Nigeria. It has become a lucrative job and an easy business to venture into since the deregulation of telecom industry in Nigeria along with the subsequent entrance of telecom service providers into the industry in Nigeria. Ernest Ndukwe (2003) analyse the role of telecommunications in national development with respect to Nigeria and he mentioned that "close to 2,000 persons have been directly employed by the GSM operators and an estimated 400,000 Nigerians are benefiting from indirect employment generated by the GSM operators". Most of these indirect employees of telecom industry are the retailers and their number is always on the increase by the day and remains infinite.

Therefore sample sizes are chosen based on some factors and among these we have availability of resources, manpower, budget and research time frame (Kanupriya Chaturvedi, 2005). In the light of these, the sample size for this research work will be 80 respondents drawn from the retailers in the chain of distribution. This study uses the simple random sampling in determining its sample size. Simple random sampling is a basic type of sampling, its basic principle is that every object in the population has the same probability of being chosen. Each individual sample is chosen randomly and entirely by chance, such that each sample has the same probability of being chosen at any stage during the sampling process (Maxwell, 2011). This study randomly selects 80 samples from the entire population of study.

For the purpose of this study primary data sourced through questionnaire will be used. Part of the advantage of using primary data is that this method helps in making reference to phenomena as they exist in real life. The research instrument for this study - the questionnaire is administered to the retailers in their respective outlets. The questionnaire comprises two (2) sections; with section "A" comprising five (5) items seeking demographic data such as age, sex, status, level of education and years of experience in the business of sales of telecommunication products and services. Section "B" consists of twenty (17) questions, which sought to collect information about the impact of trade marketing activities. The researcher enlisted the assistance of MTN staffs who work as foot soldiers to reach out to all the respondents in their respective outlets. The questions are such that the respondents can make immediate responses by ticking appropriate answers. The respondents are allowed to make written responses by ticking any appropriate options from each of the questions.

\section{Data Analysis}

Simple percentage was used to analyse section A of the questionnaire which focuses majorly on the bio-data of respondents, while the ordinary least square (OLS) method of data analysis with multiple variables was used in analysing the section B of the questionnaire. The first step in this data analysis is the specification of the model with which one will attempt the measure of the phenomenon being analysed. This stage is also known as the formulation of the maintained hypothesis, (Koutsoyianis, 2006). In line with this procedure, the model specified for this research work is such that covered a wide range of variables. The model is as follows:

Model: Revenue_Generation $=\mathrm{f}($ Outlet_Branding, Payment_Options, Incentive, Biz_Growth, Treatment $)$

$$
\text { Revenue_Generation }=\beta_{o}+\beta_{1} X_{1}+\beta_{2} X_{2}+\beta_{3} X_{3}+\beta_{4} X_{4}+\beta_{5} X_{5}+\mu
$$

Where:

Revenue_Generation $=$ Dependent variable 
Outlet_Branding, Payment_Options, Incentive, Biz_Growth, Treatment = independent variable

$\beta_{\mathrm{o}}=$ Intercept

$\beta_{1}-\beta_{5}=$ Coefficient of the variables

$\mu=$ Stochastic error term

4.1 Demographical Analysis of Study Sample

The age range of the 80 respondents to the questionnaire is as shown in the table below:

Table 1. Age Distribution of Respondents

Source: Field Survey

\begin{tabular}{lll}
\hline Age & Total & Percentage \\
\hline $18-25$ & 41 & 51.25 \\
$25-40$ & 37 & 46.25 \\
40 \& Above & 2 & 2.5 \\
\hline
\end{tabular}

The table indicate that greater percentage of the respondents (51.25\%) fall within the age $18-25$ while $46.25 \%$ are within the age $25-40$ years of age and just $2.5 \%$ of the respondents are 40 years and above. The implication of these is that more than $90 \%$ of the study sample falls within the active labour force.

Table 2. Sex Distribution of Respondents

\begin{tabular}{lll}
\hline Gender & Total & Percentage \\
\hline Male & 48 & 60 \\
Female & 32 & 40 \\
\hline
\end{tabular}

Source: Field Survey

There is $10 \%$ difference between the male and female respondents as indicate in the table above, while $60 \%$ are male the other $40 \%$ are females.

Table 3. Marital Status of Respondents

Source: Field Survey

\begin{tabular}{lll}
\hline Marital & Total & Percentage \\
\hline Married & 14 & 17.5 \\
Single & 65 & 81.25 \\
Divorced & 1 & 1.25 \\
\hline
\end{tabular}

Marital status distribution shows that 65 which represent $81.25 \%$ of the respondents are single whereas there is $1.25 \%$ representation of divorced person among the respondents and the remaining 14 individuals representing $17.5 \%$ are married.

Table 4. Educational Qualification of Respondents

\begin{tabular}{lll}
\hline Qualification & Total & Percentage \\
\hline O'level & 36 & 45 \\
OND/NCE & 35 & 43.75 \\
HND/BSC & 7 & 8.75 \\
Postgrauate & 2 & 2.5 \\
\hline
\end{tabular}

Source: Field Survey

44 out of the 80 respondents polled has $\mathrm{OND} / \mathrm{NCE}$ as their minimum educational qualification and this implies that more than half of the respondents will be capable of reading and understanding the questions of the survey without any aid. 
Table 5. Years of Experience

Source: Field Survey

\begin{tabular}{lll}
\hline Years of Experience & Total & Percentage \\
\hline 0 - 5 years & 73 & 91.25 \\
6 - 10 years & 6 & 7.5 \\
10 Years and above & 1 & 1.25 \\
\hline
\end{tabular}

$91.25 \%$ of the respondents have at most 5 years of experience in retail business while 8.75 have at least 6 years of experience.

\section{Re-Specification of Model}

The model for this research work is used in capturing the relationship among all the variables and a multiple regression is run on SPSS to obtain coefficients for the variables as well as other necessary data that will be used in testing the hypothesis. The model is as follows:

Revenue_Generation $=\mathrm{f}($ Outlet_Branding, Payment_Options, Incentive, Biz_Growth, Treatment $)$

Revenue_Generation $=\beta_{0}+\beta_{1} X_{1}+\beta_{2} X_{2}+\beta_{3} X_{3}+\beta_{4} X_{4}+\beta_{5} X_{5}+\mu$

From the regression result we have:

Revenue_Generation $=0.612+0.279 \mathrm{X}_{1}-0.095 \mathrm{X}_{2}+0.142 \mathrm{X}_{3}+0.344 \mathrm{X}_{4}-0.099 \mathrm{X}_{5}$

$\mathrm{R}^{2}=0.502$ or $50.2 \%$

$\mathrm{F}_{\text {statistic }}=14.933$

Interpretation of Model

From the estimation of the parameters, as shown by the model above there will be a 0.612 change in the revenue generation assuming all variables are constant and this is the intercept $\left(\beta_{0}\right)$ of the model, which measures the change in dependent variables assuming all the independent variables are zero. This intercept also shows a positive relationship with the dependent variable.

The coefficient of $X_{1}$ i.e $\beta_{1}$ - outlet branding has a positive relationship with revenue generation. If there is a unit change in outlet branding, there will be a 0.279 change in the revenue generation. This variable measures merchandising as one of the trade marketing mix or tools of achieving trade marketing activity. This include everything from the window display to the signage, all these attracts and directs customers around helps them to make buying decisions or directing them to wherever purchases can be made. The estimated coefficient of this variable in the model shows that there is a positive relationship between revenue and merchandising.

The coefficient of $X_{2}$ i.e $\beta_{2}$ - payment options has a negative relationship with revenue generation. If there is a unit change in payment options, there will be a 0.095 change in the revenue generation. These payment options includes discounts and allowances, the use of it is to encourage retailers to stock and give preferential treatment to an organization's products. This research model and parameter estimation indicate that the use of payment options may not increase revenue because the variable shows negative relationship with revenue generation, although the level of significance of the coefficient is low and this may indicate a weak negative relationship.

The coefficient of $X_{3}$ i.e $\beta_{3}$ - incentive has a positive relationship with revenue generation. If there is a unit change in incentive, there will be a 0.142 change in the revenue generation. Trade incentive is used as a trade marketing tool to push products through the channel distribution, it helps to increase demand through the channel. From the estimated parameter if there is an increase in trade incentive there will be a consequential increase in revenue.

The coefficient of $\mathrm{X}_{4}$ i.e $\beta_{4}$ - retailer's business growth has a positive relationship with revenue generation. If there is a unit change in retailer's business growth, there will be a 0.344 change in the revenue generation. About $66.6 \%$ of respondents to this research questionnaire believe in strong terms that the growth their businesses have experienced is due to the relationship they share with MTN and consequently this retailer's business growth is helping to increase the revenue generated by MTN.

The coefficient of $X_{5}$ i.e $\beta_{5}$ - retailer's treatment has a negative relationship with revenue generation. If there is a unit change in retailer's treatment, there will be a 0.099 change in the revenue generation. This variable measures the relevance of retailers in the distribution channel as it captures all issues around business conflict in the channel of distribution. This variable depicts a negative relationship with revenue generation which indicates that telecom service providers can survive without the retailers in reaching out to their end users. 


\subsection{Test Of Hypothesis}

This study has these null and alternative hypothesis to be tested:

$\mathrm{H}_{\mathrm{o}}$ : there is no significant relationship between the activities of trade marketing and the revenue generation.

$\mathrm{H}_{\mathrm{a}}$ : there is a significant relationship between the activities of trade marketing and the revenue generation.

In the process of hypothesis testing, the most subjective part is the a priori determination of the significance level. In general, this is an arbitrary decision, and to test this study hypothesis the level of significance $(\alpha)$ chosen is $5 \%$ (0.05).

From the regression results, the probability value $(\rho$-value) $=0.000$ (the $\rho$-value is defined as the lowest level at which a null hypothesis can be rejected.

Decision rule: once the $\rho$-value has been determined, we know that the null hypothesis is rejected for any $\alpha \geq \rho$ value, while the null hypothesis is not rejected when $\alpha \leq \rho$-value. Therefore, the $\rho$-value is an indicator of the level of admissibility of the null hypothesis: the higher the $\rho$-value, the more confidence we can have in the null hypothesis.

$$
\begin{gathered}
\text { Since } \rho \text {-value }=0.000 \\
\alpha=5 \% \text { or } 0.05
\end{gathered}
$$

since $\alpha \geq \rho$-value, i.e $0.05>0.000$ therefore we reject the null hypothesis and accept the alternative which states that there is a significant relationship between the activities of trade marketing and the revenue generation.

\section{Test of the Overall Significance of the Model}

From the regression result, the $\mathrm{R}^{2}$ value is 0.502 or $50.2 \%$ it shows that the variables in the model explains better variations in the dependent variable. $\mathrm{R}^{2}$ determines the proportion of the variation in revenue generation that is explained by the independent variables outlet branding, payment options, retailer's business growth, incentive and the treatment of retailers. We have $50.2 \%$ variation in revenue generation that is explained by those independent variables. Thus, it shows a good line of fit of the samples of our variables.

Another test of the overall significance of the model is F statistics. The test aims at finding out whether the explanatory variables do actually have any significance influence on the dependent variables. To carry out this test, we set two hypotheses as follows:

Ho: $\beta_{1}=\beta_{2}=\beta_{3}=\beta_{4}=\beta_{5}=0$

$\mathrm{H}_{\mathrm{I}}$ : not all $\beta$ 's are equal to zero

$\mathrm{V}_{1}=(\mathrm{k}-1)=(6-1)=5$ (where $\mathrm{k}$ is the total number of variables)

$\mathrm{V}_{2}=(\mathrm{n}-\mathrm{k})=(80-6)=74$ (where $\mathrm{n}$ is equal to the number of samples)

Testing at $5 \%$ level of significance

$\mathrm{F}_{\mathrm{cal}}=14.933$

$\mathrm{Ftab}=2.39$

Since $F_{\text {cal }}>F_{\text {tab }}$ (i.e $14.933>2.39$ ) we reject the null hypothesis and accept the alternative, that all the parameters are not equal to zero. This therefore shows that the chosen variables have significant influence on the dependent variables.

\section{Discussion of Findings}

The interpretation of the model of this research work as well as the testing of the hypothesis will help to find answers to the research questions raised in chapter one. Therefore, the hypothesis tested helped in accepting the alternative hypothesis which states that there is a significant relationship between the activities of trade marketing and the revenue generation. This is to understand that while the use of channel of distribution has become pertinent to telecom companies as well as other consumer products manufacturer, it is also important that the management of the members of the channel should be prioritised. The need for this is argued by Wilkinson (2001) who submits that channels of distribution can be viewed as social systems comprising a set of interdependent organizations, which perform all the activities (functions) utilized to move a product and its title from production to consumption.

Due to this interdependency there arises a need for some form of co-operation between channel members and coordination of activities. This co-operation and co-ordination is necessary in order to ensure predictability and dependability between members which will allow individual organizations to plan effectively. Also, conflict arises in channels, because members sometimes have incompatible goals, differing ideas as to the functions each should 
perform, and differing perceptions of reality. This conflict needs to be controlled so that it does not disrupt channel functioning - (Wilkinson, 2001). This research has helped to understand that trade marketing as a tool is helpful in creating the coordination and cooperation required to streamline the goals and objectives of all channel members and align these with that of the manufacturer or supplier. This have a positive effect on revenue generation as it helps to stabilise profit both to the channel members as well as to the supplier.

The need for manufacturers of consumer goods to engage the use of multiple channel in their distribution has been revealed in the interpretation of the model where the variable that measures the relevance of retailers to the survival of their supplier shows a negative relationship to revenue generation. This takes us to one of the research questions of this piece that: can telecom organisations survive without the participation of retailers? As revealed by this research the use of retailers alone as a means of reaching out to end-users in the channel of distribution will not determine the survival of any supplier or manufacturer, consequently, even if retailers do not exist or are not used by a supplier the goods or services offered can still get to the final consumer. This survival can be made possible due to the use of multichannel strategy in distribution. Of note and importance in this respect is that internet has revolutionised commerce, introducing consumers to an unprecedented level of information, as well as a powerful means of interaction between businesses and customers around the globe. Now, emerging technologies are enhancing this interaction further. Today there are more options than ever before for businesses and customers to communicate and conduct business with potential customers.

Multichannel marketing provides customers with more than one way to complete a sales transaction, such as through a retail store, a web page on the internet, or even through their smartphones. Additionally, it recognises that different consumers not only favour particular channels, but may commonly use multiple channels throughout the purchasing process - for example by finding information on a web page, but actually making the purchase at a physical store (www.marketing-school.org). The old ways of marketing, such as using print sources, telemarketing or broadcasting on radio and TV are no longer the sole focus of marketing departments in organisations, these methods are still presents (that is why majority of the respondents to this research questionnaire who probably fall within the low educational level believe that MTN business cannot survive without them), but are part of a bigger strategy that includes new media and evolve along with changing customer tastes and communication preferences.

In the light of these, telecom service providers in Nigeria are also responding to the changes in the market terrain brought about by internet and other technological advancement. This is done by increasing the number of channels through which products and services can made available to consumers - among these various channels includes banks. Consumers can now buy recharge vouchers through a short code while their account will be debited immediately for the amount recharged. Along this line as well, there is quick teller on virtually all automatic teller machines through which customers can purchase recharge vouchers. There also online websites emerging daily where products and services can be purchased, included here to is online shopping, the popular among this in Nigeria we have jumia, konga and deal day. All these online based means of accessing products and services are described as convenient channels in MTN Nigeria.

\subsection{Conclusion}

It is pertinent at this point to conclude this piece of work with simple and straightforward answers to the research questions raised at the start of the work:

1. Is there a significant relationship between trade marketing, the sales and revenue generated - it has been clearly shown that trade marketing helps in increasing sales and revenue around the outlets of retailers, it also helps in resolving business related conflicts when they arise as well as smooth out any disconnection in goals and objectives between suppliers and manufacturers. All these efforts assists in fulfilling the primary goal of increase revenue generation and better competitive position in relation to competitors.

2. Should there be more investment in trade marketing activities and reduce investment into other marketing model - the answer to this question according to the findings of this work shows that there should a balance between investment into trade marketing as well as other means of advertisement and awareness creation such that the firm can maintain positive and cordial relationship with customers both those who use electronic channels and those who patronise the traditional retailers.

3. Is there a significant relationship between trade marketing activities and growth of business among channel members - about $66 \%$ of respondents to the questionnaire of this research agreed that trade marketing activities have grown their business by creating awareness for product availability thereby directing customers to their various outlets. 
4. Does trade marketing communicate product availability to consumers better at the retailer's outlet or pointof-presence - through the effort of merchandizing, there posters and signage that provides information on products and services to potential customers at the different outlets or point-of-presence of the retailers.

5. Can telecom organisations survive without the participation of retailers - the development of information and communication technology as facilitated by the deregulation of telecommunication industry in Nigeria, has created several means through which telecom's products and services can be made available to consumers without the participation of the traditional retailers or point of purchase, therefore most organisations adopt the use of multi-channel in getting across to their final users.

\subsection{Recommendations}

Based on the findings of this research work, the following are recommended for both the telecom service providers and other suppliers who rely on channel of distribution:

$>\quad$ The traditional channel of distribution where retailers are the last on the chain still plays important role in getting products and services across to the end users. They are also vital in communicating other information that may be necessary to consumers as they decide on their choice of products or service to purchase. In the light this, timely merchandising of the retailer's outlet or point-of-presence should be done by the trade marketers, this will help consumers identify these outlets and this will also help resonate the brand name in the hearts and mind of consumers.

$>\quad$ Even though the use of retailers alone would not determine the survival of a telecom service provider because of the development of the electronic marketing channels, which employ the Internet to make goods and services available for consumers. Now suppliers can employ dual distribution or strategic channel alliances as they reach out to their teaming consumers. Because of this, individual firms would have to determine how to balance budget allocation into the push and pull marketing activities respectively. Since it has been seen that both play their roles in helping a company find their competitive place in the market, while the push marketing activities relates to the trade marketing where goods are pushed through the channels of distribution whereas the pull marketing involves the use of advertising and other means in resonating the company's brands in the hearts of consumers.

Telecom firms should improve on their customer relationship management, as it has become expedient that firms should treat their retailers or every member of the distribution channels as customers. They should employ all tools of customer relationship management in getting the attention of their customers. This is a key strategy in trade marketing and one way can be the involvement of these customers in decision making. This study has shown that it is good firms and the channel members should fine-tune their goals and objectives so that every stakeholders can be on the same page, any deviance from this can create conflict in the channel. In managing cases of conflicts when they come up, application of the customer relationship techniques would suffice.

\section{References}

Alex, E., \& Julie, W. (2011). Four Steps to Optimising Trade Promotion Effectiveness. L. E. K. Consulting, XIII(5). Andres (2012). Designing and Doing Survey Research. Sage Publication.

Bollen, A., \& Emes, C. (2008). Understanding Customer Relationships, How important is the personal touch? Ipsos Mori Britain.

Corstjens, J., \& Corstjens, M. (1995). Store Wars: The Battle for Mindspace and Shelfspace, Wiley.

Dupius, M., \& Tissier-Desbordes, E. (1996). Trade marketing and retailing: a European approach. Journal of Retailing and Consumer Services, 3(1), 43-51. Printed in Great Britain. https://doi.org/10.1016/09696989(95)00045-3

Fornari, D. (1986). Entrepreneurial autonomy and trade policies of brand producers in Italy.

Geoffrey, R. (1994). Trade Marketing Strategies: The partnership between manufacturers, brands and retailers. Butterworth-Heinemann.

Kotler, P., \& Keller, K. L. (2013). Marketing Management. Pearson Horizon $14^{\text {th }}$ edition. New York

Koutsoyianis, A. (2006). Theory of Econometrics. Second edition, Palgrave, New York.

Lawrence, A. (1983). The Management of Trade Marketing, Gower.

Maxwell (2011). Sampling Essentials. Retrieved from http://www.researchgate.net

Medi, H. (2012). Business Studies, Cambridge IGCSE Revision Guide (ebook) Retrieved September 7, 2015, from 
http://www.books.google.com

Mogens, B. (1999). Different Forms and Elements of Key Account Management and Trade Marketing, in McLoughlin, Damien and C. Horan (eds.), Proceedings of the 15th Annual IMP Conference, University College, Dublin.

Procter, \& Gamble (1993). European Society Commerce, Paris (ESCP) lecture, October.

Saylor, A. (2015). Principles of Marketing. Retrieved August 12, 2015, from http://www.saylor.org/books

Toby, D. (2013). What is the difference between Trade Marketing and Shopper Marketing? ePublication, Retrieved September 22, 2015, from http://www.tobydesforges.com

Wikipedia. (2015). Online General Encyclopaedia. Retrieved August 12, 2015.

Wilkinson, I. (2001). A History of Network and Channels Thinking in Marketing in the $20^{\text {th }}$ Century.

\section{Copyrights}

Copyright for this article is retained by the author(s), with first publication rights granted to the journal.

This is an open-access article distributed under the terms and conditions of the Creative Commons Attribution license (http://creativecommons.org/licenses/by/4.0/). 